\title{
Rancang Bangun Mobile Infant Warmer dengan Menggunakan Pemanas DC
}

\author{
Bayu Wahyudi ${ }^{(1) a}$, Mohamad Miftahudin ${ }^{(1) b}$, Iqbal Firdaus ${ }^{(2) c}$ \\ (1)Jurusan Teknik Elektro Medik, Akademi Teknik Elektro Medik Semarang, Semarang, Indonesia,50222 \\ (2) Jurusan Fisika FMIPA, Universitas Lampung,Bandar Lampung, 35145 \\ Email:abayuwahyudi@atemsemarang.ac.id, ${ }^{b}$ mhuddin1@gmail.com, ${ }^{c}$ iqbal.firdaus@fmipa.unila.ac.id
}

Diterima (26 Juni 2019), Direvisi (1 Agustus 2019)

\begin{abstract}
Infant warmer is one of the tools used to provide comfort and warmth to newborns, where the baby needs a temperature that is in accordance with the temperature in the mother's womb, which is between $34^{\circ} \mathrm{C}$ $-37^{\circ} \mathrm{C}$. This tool is made so that a newborn baby can feel the temperature outside the mother's womb will be the same as the temperature that is in the mother's womb. Until now, infant warmer still has to be connected to the PLN nets to activate it. This study aims to create and design infant warmers with DC pemanass equipped with batteries so that when the electricity dies by the PLN this tool can still be used. Data analysis results for power supply output, $12 \mathrm{~V}$ pemanas input measurement is $11.9 \mathrm{~V}$ with $0.8 \%$ error and $11.8 \mathrm{~V}$ with $1.6 \%$ error, still within the tolerance limit of 5\%. The measurement results of temperature comparison between DS18B20 sensor and thermometer, have an average difference of $0.3^{\circ} \mathrm{C}$ or $1 \%$ error, so that it is still within reasonable limits. This tool has a maximum electric power of 36 Watt which saves power usage around $80 \%$. Compared to a real device where the power needed is around 200 Watts to 300 Watt.
\end{abstract}

Keywords: Arduino, battery, DC pemanas, Infant Warmer, temperature sensor

\begin{abstract}
Abstrak.Infant warmer adalah salah satu alat yang digunakan untuk memberikan kenyamanan dan kehangatan pada bayi yang baru dilahirkan, dimana bayi tersebut membutuhkan suhu yang sesuai dengan suhu didalam rahim ibu yaitu antara $34^{\circ} \mathrm{C}-37^{\circ} \mathrm{C}$. Alat ini dibuat agar bayi yang baru lahir dapat merasakan suhu diluar rahim ibu akan sama dengan suhu yang ada di dalam rahim ibu. Hingga saat ini, infant warmer masih harus tersambung dengan jala - jala PLN untuk mengaktifkannya. Penelitian ini bertujuan untuk membuat dan merancang infant warmer dengan pemanas DC dilengkapi dengan baterai agar pada saat terjadi mati listrik oleh PLN alat ini masih bisa digunakan. Hasil analisis data untuk output power supply, pengukuran input pemanas $12 \mathrm{~V}$ adalah $11,9 \mathrm{~V}$ dengan $0,8 \%$ deviasi dan $11,8 \mathrm{~V}$ dengan $1,6 \%$ deviasi, masih masuk kedalam batas toleransi yaitu 5\%. Hasil pengukuran perbandingan suhu antara sensor DS18B20 dengan thermometer, memiliki selisih rata - rata $0,3^{\circ} \mathrm{C}$ atau $1 \%$ deviasi, sehingga masih dalam batas wajar. Alat yang dirancang ini memiliki daya listrik maksimum 36 Watt sangat menghemat penggunaan daya sekitar $80 \%$. Dibandingkan dengan alat yang sesungguhnya dimana daya yang dibutuhkan sekitar 200 Watt hingga 300 Watt.
\end{abstract}

Kata kunci: arduino, baterai, pemanas DC, Infant Warmer, sensor suhu,

\section{PENDAHULUAN}

Bayi baru lahir kehilangan panas empat kali lebih besar dari pada orang dewasa, mengakibatkan terjadinya penurunan suhu. Pada 30 menit pertama bayi dapat mengalami penurunan suhu 3$4^{\circ} \mathrm{C}$. Pada ruangan dengan suhu $20-25^{\circ} \mathrm{C}$ suhu kulit bayi turun sekitar $0,3^{\circ} \mathrm{C}$ per menit. Penurunan suhu diakibatkan oleh kehilangan panas secara konduksi, konveksi, evaporasi dan radiasi. Kemampuan bayi yang belum sempurna dalam memproduksi panas maka bayi sangat rentan untuk mengalami hipotermia [1]. Bahkan di tempat suhu hangat, bayi 
baru lahir bisa mengalami kesulitan mempertahankan panas, terutama karena cairan amnion menguap dari cairan kulit. Sementara hipotermia membunuh lebih banyak bayi, efeknya hipotermia juga bisa mematikan WHO mendefinisikan suhu normal pada bayi baru lahir $36,5-37,5^{\circ} \mathrm{C}$, dan gradasi hiporermia ringan $\left(36-36,5^{\circ} \mathrm{C}\right)$, sedang $\left(32-36^{\circ} \mathrm{C}\right)$ dan berat $\left(<32^{\circ} \mathrm{C}\right)[2]$.

Infant warmer adalah salah satu alat yang digunakan untuk memberikan kenyamanan dan kehangatan pada bayi yang baru dilahirkan, dimana bayi tersebut membutuhkan suhu yang sesuai dengan suhu didalam rahim ibu yaitu antara $34^{\circ} \mathrm{C}$ $37^{\circ} \mathrm{C}$, ini dimaksudkan agar suhu tubuh bayi dapat disesuaikan dengan lingkungannya, maka alat ini dibuat agar bayi yang baru lahir dapat merasakan suhu diluar rahim ibu akan sama dengan suhu yang ada di dalam rahim ibu[3].

Infant warmer saat ini masih harus tersambung dengan jala - jala PLN untuk mengaktifkannya. Ini akan menyulitkan bagi user untuk menggunakan alat ini saat dalam keadaan mati lampu atau jauh dari jala - jala PLN. Padahal penggunaan Infant warmer ini terbilang cukup penting guna menghindari bayi dari Hypothermia. Hal itu dikarenakan penggunaan Pemanas yang masih menggunakan arus listrik AC, yang hanya bisa didapat dari jala - jala PLN atau dari $D C$ to $A C$ Converter. Penggunaan Converter dalam rangkaian Infant warmer akan menyulitkan dan cukup rumit dalam pembuatannya. Namun sebenarnya terdapat bahan pemanas yang menggunakan arus DC sehingga tidak perlu selalu tersambung pada jala - jala PLN. Tetapi dalam pengaktifanya bisa menggunakan baterai yang memiliki keluaran DC. Berdasarkan latar belakang diatas, maka penelitian ini menarik minat penulis untuk merancang alat sebagai media pembelajaran dengan judul Rancang Bangun Infant warmer Dengan Pemanas Arus DC. Tujuan dari penelitian ini yaitu untuk membuat dan merancang Infant Warmer dengan Pemanas Arus DC menggunakan mikrokontroller Arduino Uno dan dilengkapi baterai.

\section{KAJIAN PUSTAKA}

\section{Arduino UNO}

Arduino Uno adalah prototyping platform sebuah paket berupa papan (board) elektronik (hardware) dan lingkungan pengembangan (software) yang memanfaatkan kemampuan mikrokontroler jenis tertentu[4]. Mikrokontroler yang digunakan pada Arduino Uno adalah jenis Atmel seri ATmega 328[5]. Pemograman Arduino menggunakan software Arduino IDE kemudian dilakukan pemindaian ke Arduino Uno dengan menggunakan kabel USB [6]. Mikrokontroler adalah chip atau IC (integrated circuit) yang bisa diprogram menggunakan komputer. Tujuan menanamkan program pada mikrokontroler adalah agar rangkaian elektronik dapat membaca input, memproses input tersebut dan kemudian menghasilkan output seperti yang diinginkan. Jadi mikrokontroler bertugas sebagai otak yang mengendalikan input, proses, dan output sebuah rangkaian elektonik [7]. Komponen utama arduino adalah mikrokontroler, maka arduino dapat diprogram menggunakan komputer sesuai kebutuhan [8].

Arduino merupakan perangkat keras sekaligus perangkat lunak yang memungkinkan siapa saja melakukan pembuatan prototipe suatu rangkaian elektronika yang berbasis mikrokontroler dengan mudah dan cepat[9]. Arduino UNO memuat semua yang dibutuhkan untuk menunjang mikrokontroler, mudah menghubungkamya ke sebuah komputer dengan sebuah kabel USB atau mensuplainya dengan sebuah adaptor AC ke DC atau menggunakan baterai untuk memulainya [10]. 


\section{Sensor Suhu DS18B20}

DS18B20 adalah sensor suhu digital seri terbaru dari Maxim IC. Sensor ini mampu membaca suhu dengan ketelitian 9 hingga 12-bit, rentang $-55^{\circ} \mathrm{C}$ hingga $125^{\circ} \mathrm{C}$ dengan ketelitian $\left(+/-0.5^{\circ} \mathrm{C}\right)$. Setiap sensor yang diproduksi memiliki kode unik sebesar 64-Bit yang disematkan pada masing-masing chip, sehingga memungkinkan penggunaan sensor dalam jumlah besar hanya melalui satu kabel saja (single wire data bus/1-wire protocol) [11]. Penggunaan DS18B20 Waterproof harus dikolaborasikan dengan mikrokontroler Arduino Uno[12].

\section{Pemanas DC}

Pemanas DC dibuat dari bahan Kawat Nikrom yang umumnya terbuat dari $80 \%$ nikel dan $20 \%$ kromium. Namun masih banyak komposisi dari kawat nikrom ini tergantung pada kebutuhannya. Aplikasinya sendiri biasanya sebagai pemanas yang bisa beroprasi hingga suhu $1150^{\circ} \mathrm{C}$ tergantung pada kualitas dari kombinasi bahannya.Kawat nikrom biasanya didukung oleh bahan keramik agar tidak mudah meleleh dari panas yang berlebih. Kawat nikrom sendiri memiliki suhu maksimal yakni sekitar $1400^{\circ} \mathrm{C}$. Bahan digunakan untuk mengkonstruksi atau melapisi struktur yang berhubungan dengan temperatur tinggi contohnya adalah alumina [13]. Bahan ini sangat cocok sebagai kombinasi dengan kawat nikrom karena memiliki ketahanan suhu yang sangat tinggi. Selain itu, keramik Alumina sendiri tidak mudah pecah sehingga sangat aman untuk digunakan. Meski demikian, diperlukan lilitan yang kuat antara kawat dengan keramik agar tidak mudah lepas dan panas yang disalurkan dari kawat ke keramik menjadi maksimal [14].

\section{METODE PENELITIAN}

\section{Rancang Bangun Hardware}

Rancang bangun hardware

menggunakan software simulasi elektronika proteus 7 ditunjukkan pada gambar 1 . Masing-masing titik pengukuran ditunjukkan oleh TP1 untuk mengukur tegangan input Arduino, TP2 untuk mengukur tegangan input pemanas DC, TP3 untuk mengukur tegangan output arduino, dan TP4 untuk mengukur suhu. Sumber daya dari seluruh rangkaian ini adalah $12 \mathrm{~V}$ DC, sedangkan suplay daya $5 \mathrm{~V}$ DC diambil dari pin output pada arduino. Komponen yang mendapat suplay daya $12 \mathrm{~V}$ DC ialah arduino, relay, dan pemanas. Sedangkan komponen yang mendapat suplay daya $5 \mathrm{~V}$ DC ialah sensor suhu DS18B20, LCD 2x16 berfungsi sebagai penampil karakter. LCD yang digunakan pada alat ini mempunyai lebar display 4 baris 20 kolom atau biasa disebut sebagai LCD 20X4[15]dan resistor variabel. Resistor variabel sendiri berfungsi sebagai selector atau sebagai penyeting suhu yang diinginkan.

\section{Rancangan Penelitian}

Tahapan perancangan penelitian ini bertujuan untuk menjawab permasalahan dalam rangka merumuskan kesimpulan. gambar 2 berikut prosedur rancangan penelitian.Dari sumber tegangan PLN, tegangan akan diubah menjadi arus DC dan diturunkan pada power supply. Dari power supply arus akan masuk kedalam baterai sebagai backup daya hingga akhirnya arus akan disuplay ke seluruh komponen termasuk pemanas. Saat alat menyala, sensor akan langsung membaca suhu yang ada yang kemudian dikirimkan ke dalam rangkaian driver untuk kemudian dibaca. Setelah sinyal dari sensor dibaca, maka driver akan menampilkan nilai pada LCD 2x16 yang merupakan hasil konversi dari sinyal yang diberikan oleh sensor suhu dan memberikan sinyal agar pemanas menyala. 
Suhu dicatat ketika sudah mencapai kondisi suhu yang telah ditentukan. Panas dari pemanas kemudian akan terus dibaca dan dikirim oleh sensor ke rangkaian driver untuk selalu menjaga suhu yang ada. Ketika suhu mencapai nilai yang telah disetting, maka driver akan otomatis mematikan pemanas sehingga tidak terjadi overheat.

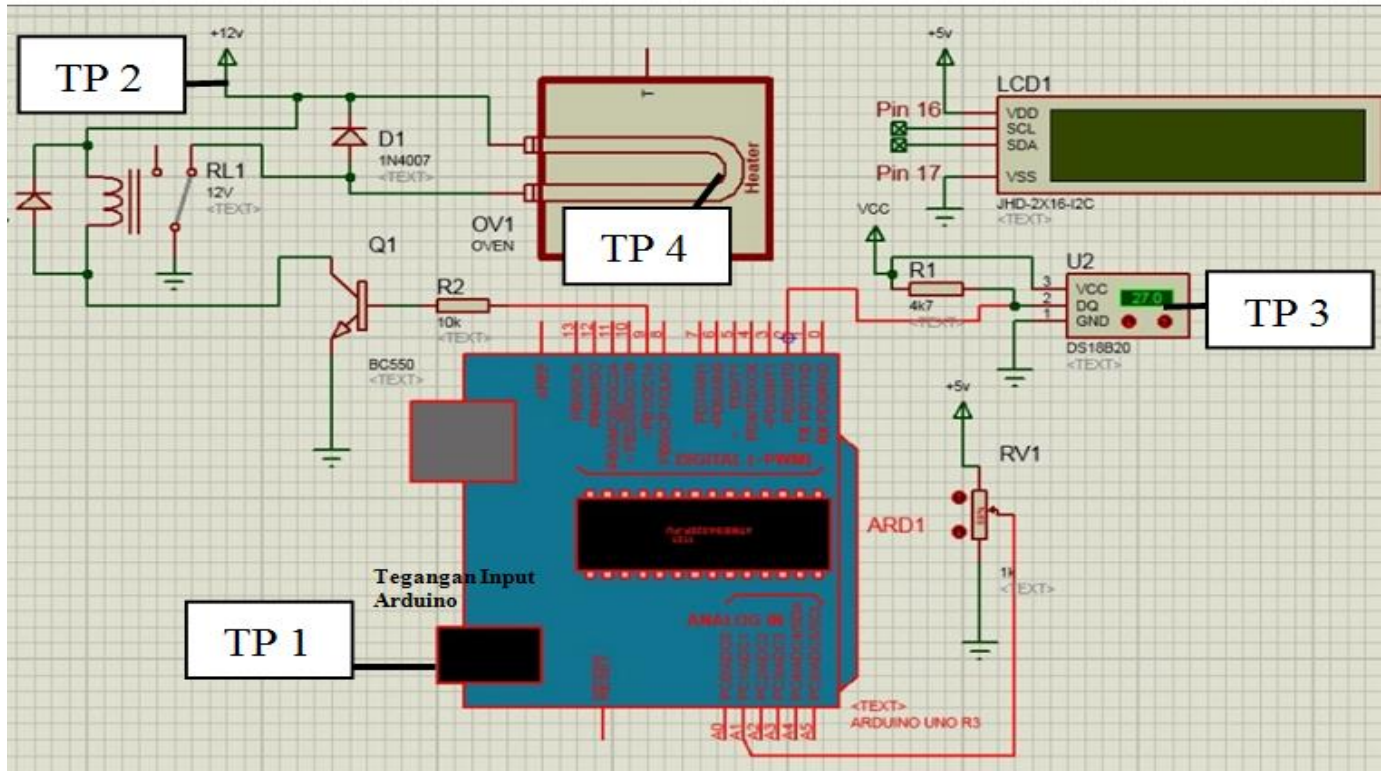

Gambar 1. Rangkaian Keseluruhan

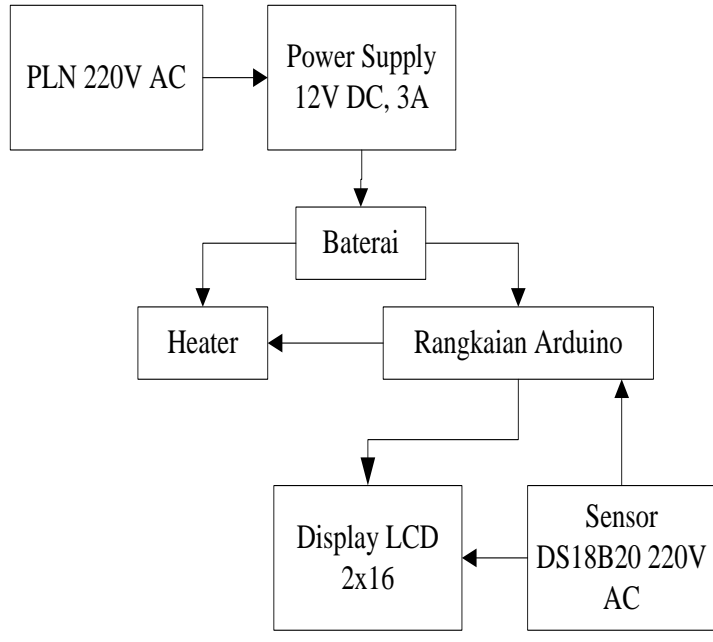

Gambar 2.Blok Diagram Alat

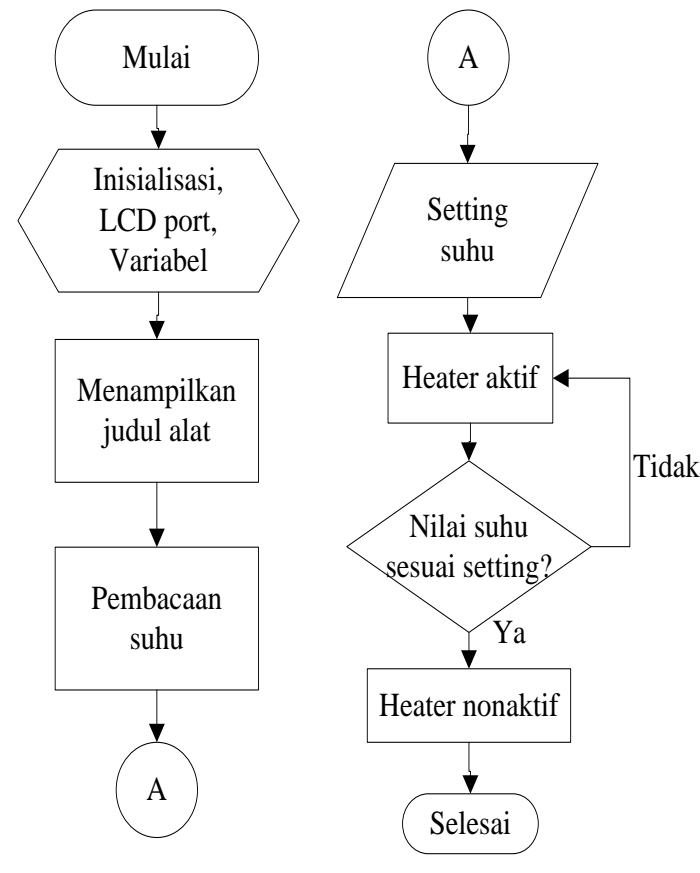

Gambar 3. Flowchart Sistem Kerja Alat 


\section{Flowchart Sistem Kerja Alat}

Berdasarkan pada gambar 3, pada saat tombol $O N$ ditekan (START) sistem alat akan mulai menginisialisasi LCD, Port dan Variabel yang kemudian menampilkan judul alat. Dari situ alat akan mulai melakukan pembacaan suhu dan menampilkannya pada LCD 2x16 dan mulai menyalakan pemanas.Kemudian barulah suhu disetting yang akan ditampilkan pada layar. Ketika sensor mendeteksi bahwa suhu belum mencapai suhu setting, maka pemanas akan tetap menyala hingga suhu yang dibaca telah sama atau kurang satu, maka pemanas akan dimatikan guna menghindari overheat.

\section{HASIL DAN PEMBAHASAN}

Titik Pengukuran 1 Pada Power Supply (TP1)

Pengukuran dilakukan pada rangkaian output power supply. Hasil pengukuran output power supply ditunjukan pada tabel 1. Hasil pengukuran pada output power supply dengan menggunakan multimeter analog merk HELES YX360TRD. Dari hasil tabel 3.1 hasil pengukuran output power supply didapatkan hasil data rata-rata tegangan terukur adalah $11,9 \mathrm{~V}$.

Tabel 1. Hasil Pengukuran Power Supply

\begin{tabular}{llllllll}
\hline \multicolumn{7}{c}{ Pengukuran Tegangan (V) } \\
\hline $\begin{array}{l}\text { Pengukur } \\
\text { an ke }\end{array}$ & 1 & 2 & 3 & 4 & 5 & $\begin{array}{l}\text { Rata } \\
\text {-rata }\end{array}$ \\
$\begin{array}{l}\text { Data } \\
\text { Terukur }\end{array}$ & 11,8 & 11,8 & 11,7 & 11,9 & 11,7 & 11,9 \\
$\left(x_{i}-\bar{x}\right)^{2}$ & 0.01 & 0.01 & 0.04 & 0 & 0.04 & 0.1
\end{tabular}

Untuk mengetahui persentase deviasi dengan perbandingan antara standar deviasi pengukuran terhadap nilai rataratanya.Persentase deviasi dari table 1 dapat diketahui dengan persamaan (1) sebagai berikut.

Persentase deviasi $=\frac{S d}{\bar{x}} \cdot 100 \%$

$$
\begin{aligned}
& =\frac{\sqrt{\frac{\sum_{i=1}^{n}\left(x_{i}-\bar{x}\right)^{2}}{n-1}}}{\bar{x}} \cdot 100 \% \\
& =\frac{\sqrt{\frac{0.1}{4}}}{11,9} \cdot 100 \% \\
& =\frac{0,158}{11,9} \cdot 100 \% \\
& =1.3 \%
\end{aligned}
$$

Hasil persentase deviasi pada output power supply adalah $1,3 \%$. Toleransi output power supply $\pm 5 \%$ untuk power supply +12VDC, sehingga output power supply diatas masih dalam batas toleransi.

\section{Pengukuran Daya Alat}

Pengukuran dilakukan pada bagian input alat atau output power supply dengan cara mengukur tegangan dan arus guna menghitung konsumsi daya listrik. Berikut merupakan hasil pengukuran yang ditunjukan pada tabel dibawah ini :

Tabel 2. Hasil Pengukuran Tegangan dan Arus

\begin{tabular}{ccccc}
\hline $\begin{array}{c}\text { Pengu } \\
\text { kuran } \\
\text { ke }-\end{array}$ & $\begin{array}{c}\text { Tegangan } \\
(\mathrm{V})\end{array}$ & $\begin{array}{c}\text { Rata }- \\
\text { rata } \\
(\mathrm{V})\end{array}$ & Arus (A) & $\begin{array}{c}\text { Rata } \\
\text { rata } \\
(\mathrm{A})\end{array}$ \\
\hline 1 & 11,9 & & 3 & \\
2 & 11,9 & 11,86 & 3 & 3 \\
3 & 11,8 & & 3 & \\
\hline
\end{tabular}

Hasil pengukuran pada inputan pemanas DC dengan menggunakan multimeter analog merk HELES YX360TRD. Dari hasil tabel 2 hasil pengukuran tegangan dan arus pada output power supply didapatkan hasil data rata - 
rata tegangan $11,86 \mathrm{~V}$ dan rata - rata arus 3A. Daya Listrik dapat diketahui dengan persamaan (2) sebagai berikut :

$\mathrm{P}=\mathrm{V} \times \mathrm{I}$

Dimana :

- $\quad \mathrm{P}=$ Watt (Daya Listrik)

- $\quad \mathrm{V}=$ Voltase (Tegangan)

- $\quad \mathrm{I}=$ Ampere (Arus)

Berdasarkan pada persamaan (2), maka dapat diketahui daya pada alat peneliti :

$$
\begin{aligned}
& \mathrm{P}=\mathrm{V} \times \mathrm{I} \\
& \mathrm{P}=11,86 \times 3 \\
& \mathrm{P}=35,6 \text { Watt. }
\end{aligned}
$$

Analisa data dari hasil perhitungan daya listrikdiatas. Hasil daya listrik pada output power supply adalah 35,6 Watt. Dibandingkan dengan alat yang sesungguhnya, yang telah beredar di pasaran dimana rata - rata konsumsi daya listrik alat sekitar 200 Watt sampai 300 Watt, maka alat peneliti jauh lebih menghemat daya.

\section{Titik Pengukuran 2 Pada Input Pemanas}

Pengukuran dilakukan pada rangkaian pemanas DC. Pengukuran dilakukan pada titik tegangan masukan yang digunakan pemanas DC yang berfungsi untuk memancarkan panas. Berikut merupakan hasil perhitungan yang ditunjukkan pada tabel 3 dibawah ini :

Tabel 3.Hasil Pengukuran Tegangan Pemanas DC

\begin{tabular}{lcccccc}
\hline \multicolumn{7}{c}{ Pengukuran Tegangan $(\mathrm{V})$} \\
\hline $\begin{array}{l}\text { Penguku } \\
\text { ran ke - }\end{array}$ & 1 & 2 & 3 & 4 & 5 & $\begin{array}{l}\text { Rata } \\
\text {-rata }\end{array}$ \\
Data & 11,6 & 11,7 & 11,8 & 11,8 & 11, & 11,8 \\
Terukur & & & & & 8 & \\
$\left(x_{i}\right.$ & 0.04 & 0.01 & 0 & 0 & 0 & 0.05 \\
$-\bar{x})^{2}$ & & & & & & \\
\hline
\end{tabular}

Pengukuran persentase deviasi pada TP2 inputan pemanas DC menggunakan persamaan (1).

$$
\begin{aligned}
\text { Persentase deviasi } & =\frac{\sqrt{\frac{0.05}{4}}}{11,8} \cdot 100 \% \\
& =\frac{0,111}{11,8} \cdot 100 \% \\
& =0.9 \%
\end{aligned}
$$

Analisa dan hasil dari Tabel 2 menunjukan bahwa tegangan input pemanas DC memiliki persentase deviasi $0.9 \%$. Namun karena efek yang dihasilkan dari deviasi input tegangan tidak terlalu besar (tidak lebih dari $\pm 5 \%$ ), masih dalam batas toleransi.

\section{Titik Pengukuran 3 Pada Nilai Suhu}

Pengukuran dilakukan pada rangkaian sensor suhu dan ditampilkan dalam LCD $2 \times 16$. Pengukuran dilakukan dengan cara perbandingan antara nilai yang tertera pada LCD 2x16 dengan thermometer ruangan. Berikut merupakan hasil dari perhitungan dan pengukuran yang ditunjukan pada tabel 4 dibawah ini :

Tabel 4. Hasil Pengukuran Nilai Suhu, Perbandingan Nilai Ukur Alat yang Diteliti dengan Thermometer.

\begin{tabular}{llll}
\hline $\begin{array}{l}\text { Pengu- } \\
\text { kuran } \\
\text { ke }\end{array}$ & $\begin{array}{l}\text { Mobile } \\
\text { Infant } \\
\text { Warmer } \\
\left({ }^{\circ} \mathrm{C}\right)\end{array}$ & $\begin{array}{l}\text { Thermo- } \\
\text { meter } \\
\left({ }^{\circ} \mathrm{C}\right)\end{array}$ & $\begin{array}{l}\text { Selisih } \\
\left({ }^{\circ} \mathrm{C}\right)\end{array}$ \\
\hline 1 & 28 & 28 & 0 \\
2 & 29 & 29 & 0 \\
3 & 30 & 29 & 1 \\
4 & 30 & 30 & 0 \\
5 & 30 & 30 & 0 \\
\hline
\end{tabular}

Hasil pengukuran suhu pada alat mobile infant warmer menunjukkan selisih $0{ }^{\circ} \mathrm{C}$ pada pengukuran 1,2,4 dan 5. Pada pengukuran ke-4 menunjukan selisih $1{ }^{\circ} \mathrm{C}$. Pada datasheet sensor suhu DS18B20 sendiri memiliki toleransi suhu alat yang 


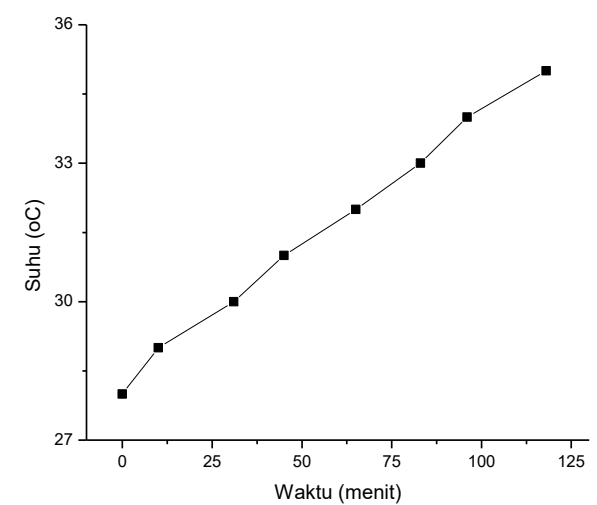

Gambar 4. Grafik waktu pemanasan

diperbolehkan adalah maksimum $\pm 1^{\circ} \mathrm{C}$. Dengan demikian nilai suhu yang terukur masih dalam batas toleransi.

Hasil pengukuran waktu pemanasan ditunjukkan pada gambar 4, dengan kondisi ruangan tidak ber-AC dengan suhu awal pengukuran $28^{\circ} \mathrm{C}$. Dari nilai suhu awal $28^{\circ} \mathrm{C}$ kemudian naik $1^{\circ} \mathrm{C}$ membutuhkan waktu 10 menit, kemudian kenaikan $1{ }^{\circ} \mathrm{C}$ berikutnya, rata-rata waktu yang dibutuhkan adalah 17,4 menit. Untuk mencapai suhu $35{ }^{\circ} \mathrm{C}$ membutuhkan waktu yang lama yaitu 118 menit. Alat ini membutuhkan waktu pemanasan yang lama, tetapi konsumsi daya listriknya rendah yaitu 35,6 watt.

\section{KESIMPULAN}

Alat mobile infant warmer dengan Pemanas DC dilengkapi baterai, dapat beroperasi dengan arus DC $12 \mathrm{~V}$ dan arus 3A. Menggunakan kawat nikelin dengan panjang 1 meter dan diameter $0,5 \mathrm{~mm}$ yang dililitkan pada keramik alumina $\left(\mathrm{Al}_{2} \mathrm{O}_{3}\right)$ sebagai pemanasnya. Hasil analisis data untuk output power supplay $12 \mathrm{~V}$ adalah $11,9 \mathrm{~V}$ atau $0,8 \%$ deviasi sehingga masih dalam batas toleransi power supply yaitu $\pm 5 \%$. Hasil pengukuran input pemanas, didapatkan nilai $11,8 \mathrm{~V}$ atau $1,6 \%$ deviasi masih dalam batas toleransi. Hasil pengukuran perbandingan suhu antara sensor DS18B20 dengan termometer, memiliki selisih rata - rata $0,3^{\circ} \mathrm{C}$ atau $1 \%$ deviasi, sehingga masih dalam batas wajar. Kawat nikelin dengan panjang 1 meter dan diameter $0,5 \mathrm{~mm}$ mampu aktif dengan tegangan $12 \mathrm{~V}$ dan arus DC $3 \mathrm{~A}$, suhu maksimum yang dapat dicapai adalah $35^{\circ} \mathrm{C}$ meskipun memiliki kecepatan pemanasan yang terbilang lama. Jika berdasarkan pada rumus Daya Listrik $(\mathrm{P}=\mathrm{V}$ x I) maka alat yang dirancang penulis memiliki daya listrik maksimum 36 Watt. Berbeda jauh dengan alat yang sesungguhnya dimana daya yang dibutuhkan sekitar 200 Watt hingga 300Watt. Fungsi dari baterai sendiri sebagai pengaman, serta sebagai backup daya ketika tidak ada sumber listrik di sekitar alat.

\section{DAFTAR PUSTAKA}

[1] H. S. Hutagaol, E. Darwin, and E. Yantri, "Pengaruh Inisiasi Menyusu Dini (IMD) terhadap Suhu dan Kehilangan Panas pada Bayi Baru Lahir," J. Kesehat. Andalas, vol. 4, no. 4, pp. 32-38, 2014.

[2] A. Proverati, BBLR- Berat Badan Lahir Rendah: Plus Asuhan pada BBLR dan Materi Pijat Bayi. Yogyakarta: Nuhu Medika, 2010.

[3] S. Heri and Suryono, "Rancang Bangun Sistem Pengaturan Suhu Ruang Inkubator Bayi Berbasis Microcontroller AT89S51," J. Berk. Fis., vol. 12, no. 2, pp. 55-63, 2009.

[4] M. Adali, M. Daus, and R. Putri, "Perancangan Alat Ukur Digital untuk Tinggi dan Berat Badan dengan Output Suara berbasis Arduino UNO," J. Elkomika, vol. 5, no. $1,2017$.

[5] A. Yoga and L. Rachmawati, "Alat Ukur Panjang Dan Berat Badan Balita Untuk Menentukan Kategori Status Gizi Berbasis Arduino Uno," in Jurusan Teknik Elektro Unesa, 2018, vol. 07, no. 01, pp. 1-8. 
[6] A. Susanto, A. A. Muslim, and S. Mubarok, "Pemecahan Bitmap Pada Led Dot Matrix F3.75 Menggunakan Arduino Uno Sebagai Pembentuk Karakter," J. Elektro dan Inform., vol. 3, no. 1, pp. 1-4, 2018.

[7] Y. M. Dinata, Arduino Itu Mudah. Jakarta: PT Elex Media Komputindo, 2015.

[8] E. P. Agfianto, Belajar Mikrokontroller AT89CS1/25/55: Teori dan Aplikasi. Yogyakarta: Gava Media, 2003.

[9] A. Kadir, Pemrograman Arduino dan Processing. Jakarta: Gramedia, 2017.

[10] A. Kadir, Simualasi Arduino. Jakarta: PT Elex Media Komputindo, 2016.

[11] E. Nurazizah, M. Ramdhani, and A.
Rizal, "Rancang Bangun Termometer Digital Berbasis Sensor DS18B20 Untuk Penyandang Tunanetra," Proceeding Eng., vol. 4, no. 3, pp. 3294-3301, 2017.

[12] I. Abdul Rozaq, "Uji Karakterisasi Sensor Suhu Ds18B20 Waterproof Berbasis Arduino Uno Sebagai Salah Satu Parameter Kualitas Air," Pros. SNATIF Ke-4 Tahun 2017, vol. 4, pp. 303-309, 2017.

[13] T. Surdia and S. Saito, Pengetahuan Bahan Teknik. 1999.

[14] M. R. Rahmat, "Perancangan Dan Pembuatan Tungku Heat Treatment," J. Ilm. Tek. Mesin, vol. 3, no. 2, pp. 133-148, 2015.

[15] S. I. Inc, Liquid Crystal Display Module M2004. 2011. 